\title{
Polyphenol composition and antioxidant potential of mint leaves
}

\author{
Nicole Brown ${ }^{1}$, Jenny A. John ${ }^{1,2}$ and Fereidoon Shahidi $i^{*}$
}

\begin{abstract}
Soluble and insoluble/bound phenolic compounds and an aqueous infusion of two mint species (Medina and Hasawi), were tested for their total phenolic content, 2,2'-azino-bis-3-ethylbenzthiazoline-6-sulphonate (ABTS) and 1,1-diphenyl2picrylhydrazyl (DPPH) radical scavenging activity, iron (III) reduction, iron (II) chelating and oxygen radical absorbance capacity (ORAC). Furthermore, the potency of the mint extracts in the inhibition of radical-induced DNA scission, human low-density lipoprotein (LDL) cholesterol oxidation, formation of thiobarbituric acid reactive substances (TBARS) in a cooked ground meat system and LPS (lipopolysaccharide)-stimulated cyclooxygenase-2 (COX-2) expression in J774A.1 mouse macrophage cells were monitored. Results showed that the soluble phenolics had a higher phenolic content and antioxidant activity than the insoluble-bound extracts and aqueous infusions in most of the assays. Both varieties exhibited notable antioxidant activities and inhibition of LDL cholesterol oxidation, DNA scission and COX-2 gene expression at transcriptional level. However, Medina mint was a more potent antioxidant than the Hasawi mint. High performance liquid chromatography with online tandem electrospray ionization mass spectrometry (HPLC/ESI-MS/MS) analysis of the extracts revealed that rosmarinic acid was the major phenolic compound present in both mint samples.
\end{abstract}

Keywords: Mint, Phenolic compounds, Antioxidant activity, Rosmarinic acid, HPLC/ESI-MS/MS

\section{Introduction}

Spices and herbs are known to serve as powerful antioxidants. Members of the Lamiaceae family such as mint, basil, rosemary, sage, savory, oregano, and thyme, are particularly well known for their use in food and traditional medicine (Park 2011). Extracts of rosemary and sage are routinely used to control oxidation of food lipids (Zheng and Wang 2001; Shahidi and Zhong 2010). These products are now commercially available in the deflavored form. Aqueous infusions obtained from mint leaves have long been used to treat anorexia, hypertension, and many spasmolytic and gastrointestinal problems (Mimica-Dukic and Bozin 2008). In addition, mint has been shown in clinical trials to treat headaches through analgesic properties, reduce painful muscle spasms in patients undergoing endoscopy of the upper and lower gastrointestinal (GI) tract, and reduce abdominal pain and dyspepsia (McKay and Blumberg 2006). In vitro-based studies have also demonstrated the potential

\footnotetext{
*Correspondence: fshahidi@mun.ca

${ }^{1}$ Department of Biochemistry, Memorial University of Newfoundland, St. John's, NL A1B 3X9, Canada

Full list of author information is available at the end of the article
}

anti-depressant effects of mint extracts (Lopez et al. 2010). Many of these medicinal effects of mint are closely associated with the high content of phenolic compounds; the phenolics from mint tea and mint extracts have been shown to exhibit antimicrobial and antiviral activities (Mimica-Dukic and Bozin 2008). Additionally, mint extract has been shown to increase cellular superoxide dismutase activity, a natural protective mechanism against oxidative damage (Mimica-Dukic et al. 1996).

Phenolics belong to an important class of compounds responsible for the antioxidant activity of mint. Previous studies have found the total polyphenolic content of peppermint leaves to be approximately $19-23 \%$ with total flavonoids of $12 \%$ (McKay and Blumberg 2006). Mata et al. (2007) reported that the main active components in mint were eriocitrin, rosmarinic acid, luteolin 7-O-rutinoside, hesperidin, and small quantities of pebrellin, gardenin B and apigenin. Another study determined the major polyphenols in mint as rosmarinic acid, caffeic acid, ferulic acid and eugenol (Tahira et al. 2011). 
Phenolic compounds are, however, not distributed evenly throughout different parts and sections of the plant. The outer layers of plants often contain higher levels of phenolics than their interior parts. For example, many different studies have shown that there is a higher phenolic content in the peels of fruits and vegetables than in the flesh (Kujala et al. 2000; Tomas-Barberan et al. 2001). At a cellular level, insoluble-bound phenolics are often linked to components of cell walls and soluble phenolics are located within plant cell vacuoles as either free phenolic acids, esterified to pectins and arabinoxylans, or cross-linked to cell wall polysaccharides in the form of dimers (Naczk and Shahidi 2004). In the present study, a modified version of the method described by Krygier et al. (1982) and Naczk and Shahidi (1989) was used to extract both the soluble and insoluble-bound phenolics.

In this work, the antioxidant activity and phenolic content of two mint varieties grown in Saudi Arabia were determined. Solvent extracts of both soluble and insoluble phenolics were prepared and dechlorophyllized to determine their potential use as a natural antioxidant. Furthermore, an aqueous mint infusion was prepared and analyzed to quantify the amount of polyphenols extracted during normal cooking procedures or in tea preparation as used traditionally, and to determine its efficiency to act as an antioxidant. A cooked meat model system was also used, in addition to other in vitro tests of antioxidant activity, to determine the effectiveness of mint samples as natural food preservatives. The phenolic compounds present in the mint extracts were identified using high performance liquid chromatography with online tandem electrospray ionization mass spectrometry (HPLC/ESIMS/MS). Since no information on determination of polyphenols in mint cultivars from local sources in Saudi Arabia is available, this investigation provides basic information for further work on antioxidant potential in herbs and medicinal plants.

\section{Materials and methods}

\section{Materials}

Dried leaves of Medina and Hasawi mint were kindly provided by Professor A.S. Al-Khalifa. Human LDL cholesterol was purchased from Sigma-Aldrich, St. Louis, MO, USA. Supercoiled plasmid DNA (pBR322, $43 \mathrm{kbp}$ ) was procured from Promega Corporation, Madison, WI, USA, and SYBR safe gel stain was from Invitrogen Molecular Probes, Eugene, OR, USA. Trolox (6-hydroxy-2,5,7,8-tetramethylchroman-2-carboxylic acid) was purchased from Acros Organics (Fair Lawn, NJ, USA). Organic solvents and reagents such as methanol, acetone, and sodium carbonate were obtained from Fisher Scientific (Nepean, ON, Canada). Folin-Ciocalteu phenol reagent, 2,2'-azobis (2- methylpropionamidine) dihydrochloride (AAPH), 2,2'azino-bis (3-ethylbenzthiazoline-6-sulphonic acid) (ABTS), 2,2-diphenyl-1-picrylhydrazyl (DPPH), and all phenolic standards were bought from Sigma-Aldrich Canada Ltd. (Oakville, ON, Canada).

\section{Sample preparation}

Extraction of phenolic compounds from Medina and Hasawi mint was performed by the method described by Krygier et al. (1982). Medina and Hasawi mint leaves were ground to a fine powder and about $10 \mathrm{~g}$ of each were mixed with $150 \mathrm{~mL}$ of methanol/acetone/water (7:7:6, v/v/ v). These samples were sonicated at $40{ }^{\circ} \mathrm{C}$ for $20 \mathrm{~min}$ (Ultrasonik, Whittemore Enterprises, Inc., Rancho Cucamonga, CA, USA), then centrifuged for $5 \mathrm{~min}$ at $4000 \mathrm{~g}$. Once centrifuged, the supernatant was collected and the extraction procedure was repeated two more times. The solvent from combined supernatants was removed in vacuo at $40^{\circ} \mathrm{C}$ using a Rotavapor (Buchi, Flawil, Switzerland), frozen at $-80^{\circ} \mathrm{C}$ for about $4 \mathrm{~h}$ and lyophilized for 5 days at $-48^{\circ} \mathrm{C}$ and $4.6 \times 10^{-4}$ mbar (Freezone, Labconco Co., Kansas City, MO, USA) yielding the crude extract of the soluble phenolic compounds.

To prepare the bound-insoluble phenolic extracts, the residue obtained from the extraction of soluble phenolics was hydrolyzed according to the procedure outlined by Krygier et al. (1982) and Naczk and Shahidi (1989). Briefly, $25 \mathrm{~mL}$ of $4 \mathrm{M} \mathrm{NaOH}$ were added to the residue in a round bottom flask with a stirring bar. The flask was flushed with nitrogen, sealed, and allowed to stir for $4 \mathrm{~h}$. The mixture was then acidified using $6 \mathrm{M} \mathrm{HCl}$ to a $\mathrm{pH}$ of 2 and was then centrifuged at $2000 \mathrm{~g}$ for $5 \mathrm{~min}$. The supernatant was extracted with an equal volume of hexane to remove fatty acids released during alkaline hydrolysis. Extraction of bound phenolics was achieved by mixing the supernatant with an equal volume of 1:1 (v/ v) diethyl ether/ethyl acetate, three times. The ether layer was filtered through anhydrous sodium sulphate in a No. 1 Whatman filter paper and the sample was dried in vacuo at room temperature (Rotavapor, Buchi, Flawil, Switzerland). The bound phenolics were reconstituted in $5 \mathrm{~mL}$ of $80 \%$ methanol and stored at $-20^{\circ} \mathrm{C}$ until use.

To dechlorophyllize the crude soluble phenolic extracts and the crude insoluble-bound extracts of the mint samples, $1.0 \mathrm{~g}$ of each was dissolved in $50 \mathrm{~mL}$ of $80 \%$ methanol following the method described by Alvarez-Parrilla et al. (2011). In a separatory funnel, $100 \mathrm{~mL}$ of dichloromethane were added to each extract solution and the organic phase was removed. Chlorophyll was extracted a second time with $15 \mathrm{~mL}$ dichloromethane and the organic layer was removed again. Methanol was removed from the extracts in vacuo, at about $50{ }^{\circ} \mathrm{C}$ and 66 mbar (Rotavapor, Buchi, Flawil, Switzerland). The dechlorophyllized soluble 
phenolic extracts were allowed to freeze at $-80^{\circ} \mathrm{C}$ and lyophilized for about $72 \mathrm{~h}$.

The aqueous infusions were prepared according to the method outlined by Moraes-de-Souza et al. (2008). Dried powder samples of Medina and Hasawi mint leaves $(3.0 \mathrm{~g})$ were steeped in $200 \mathrm{~mL}$ of boiling deionized water for $10 \mathrm{~min}$. The mixture was filtered through a Whatman No. 1 filter paper and stored at $4{ }^{\circ} \mathrm{C}$ in a glass bottle. This solution was made fresh weekly throughout the study.

\section{Determination of total phenolics}

The determination of total phenolics was carried out according to the Folin-Ciocalteau's reagent assay as described by Singleton and Rossi (1965), with minor modifications. Gallic acid was used as a standard and values were expressed as $\mathrm{mg}$ gallic acid equivalents $(\mathrm{GAE}) / 100 \mathrm{~g}$ of dried sample. Each sample was diluted to fit within the absorbance values for the standard curve.

\section{Radical scavenging based antioxidant activity tests Trolox equivalent antioxidant capacity (TEAC) assay}

The TEAC assay is based on scavenging of $2,2^{\prime}$-azinobis-3-ethylbenzthiazoline-6-sulfonate radical cation $\left(\right.$ ABTS $^{+}{ }^{+}$. The TEAC assay was performed using a modified version of the method described by Chandrasekara and Shahidi (2010). Briefly, an ABTS. ${ }^{+}$solution was prepared by mixing equal volumes of $2.5 \mathrm{mM}$ AAPH with $2.0 \mathrm{mM}$ ABTS in $100 \mathrm{mM}$ saline phosphate buffer (PBS; $\mathrm{pH} 7.4,0.15 \mathrm{M} \mathrm{NaCl}$ ). The mixture was heated to $60^{\circ} \mathrm{C}$ and kept there for $12 \mathrm{~min}$ while wrapped in aluminum foil to protect it from light. The solution was filtered several times throughout the experiment using a No. 1 filter paper and was used entirely within $2 \mathrm{~h}$. All samples were diluted in PBS to fit within the absorbance range of the standard curve. In triplicate, each diluted sample $(40 \mu \mathrm{L})$ or trolox standard was added to $1.96 \mathrm{~mL}$ of the ABTS. $^{+}$solution, vortexed briefly, and allowed to react at ambient temperature. The absorbance at $734 \mathrm{~nm}$ was read exactly $6 \mathrm{~min}$ after the reagents were mixed. TEAC values were expressed as mmoles trolox equivalents (TE) per $100 \mathrm{~g}$ of initial dried sample and were calculated based on the prepared standard curve.

\section{DPPH radical scavenging capacity (DRSC)}

The DPPH radical scavenging assay described by Chandrasekara and Shahidi (2011) was adapted with slight modifications. Samples were prepared by dilution in methanol to obtain values within the trolox standard curve. Two milliliters of DPPH solution in methanol $(0.18 \mathrm{mM})$ were added to $0.5 \mathrm{~mL}$ of the diluted samples. Contents were mixed well and, after $10 \mathrm{~min}$, were injected into an electron paramagnetic resonance (EPR) spectrometer (Bruker Biospin Co., Billercia, MA, USA). The parameters were set as follows: $5.02 \times 10^{2}$ receiver gain, $1.86 \mathrm{G}$ modulation amplitude, $2.621 \mathrm{~s}$ sweep time, 8 scans, $100.000 \mathrm{G}$ sweep width, 3495.258 G center field, $5.12 \mathrm{~ms}$ time constant, $9.795 \mathrm{GHz}$ microwave frequency, and $86.00 \mathrm{kHz}$ modulation frequency. The height of the highest peak was recorded (in this case, it was always the second positive peak) and the percentage of the remaining radical scavenging capacity was calculated according to the following equation.

$$
\begin{aligned}
\% \mathrm{DRSC}= & 100-(\mathrm{EPR} \text { signal of the sample }) \\
& /(\text { EPR signal of control }) \times 100 .
\end{aligned}
$$

Trolox $(15.625-200 \mu \mathrm{M})$ was used as a standard and the results were reported as mmoles TE per $100 \mathrm{~g}$ of initial dried sample.

\section{Oxygen radical absorbance capacity (ORAC) assay}

The ORAC assay was performed according to Madhujith and Shahidi (2007) with slight modifications, using a FLUOstar OPTIMA microplate reader (BMG Labtech, Durham, NC, USA). The internal wells of a nontransparent 96-well microplate (Costar Corning Inc., Corning NY, USA) were used in the ORAC assay. Solutions were prepared, in triplicate, by mixing $20 \mu \mathrm{L}$ of diluted sample or trolox standard $(10-100 \mu \mathrm{M}$ dissolved in $75 \mathrm{mM}$ phosphate buffer, $\mathrm{pH} 7.4$ ) with $200 \mu \mathrm{L}$ of $0.11 \mu \mathrm{M}$ fluorescein $\left(3^{\prime}, 6^{\prime}\right.$-dihydroxyspiro [isobenzofuran-1(3H), $9^{\prime}$-[9H]xanthen]-3-one) directly in the microplate. These solutions were incubated at $37^{\circ} \mathrm{C}$ in a FLUOstar OPTIMA microplate reader for $15 \mathrm{~min}$ before $75 \mu \mathrm{L}$ of $63.4 \mathrm{mM}$ AAPH (in $75 \mathrm{mM}$ phosphate buffer, pH 7.4) were automatically injected. Excitation and emission (at 485 and $520 \mathrm{~nm}$, respectively) were measured every $3.5 \mathrm{~min}$ for $87.5 \mathrm{~min}$ with shaking $8 \mathrm{~s}$ prior to each cycle. ORAC values were calculated from the area under the fluorescence decay curves between blank and samples and were reported as mmol TE per $100 \mathrm{~g}$ of initial dried sample.

\section{Reducing power}

The reducing power of the samples was determined according to the method described by Yen and Chen (1995). Briefly, a mixture of $1.0 \mathrm{~mL}$ of sample or trolox standard (diluted in $0.2 \mathrm{M}$ phosphate buffer), $2.5 \mathrm{~mL}$ of $0.2 \mathrm{M}$ phosphate buffer, and $2.5 \mathrm{~mL}$ of $1 \%(\mathrm{w} / \mathrm{v})$ potassium ferricyanide was incubated at $50{ }^{\circ} \mathrm{C}$ for $20 \mathrm{~min}$. Two and a half milliliters of $10 \%$ trichloroacetic acid $(\mathrm{TCA}, \mathrm{w} / \mathrm{v})$ were then added and the mixture was centrifuged at $2000 \mathrm{~g}$ for $10 \mathrm{~min}$. For the assay solution, 1.0 $\mathrm{mL}$ of the supernatant was added to $2.5 \mathrm{~mL}$ deionized water and $0.5 \mathrm{~mL}$ of $0.1 \%$ ferric chloride $(\mathrm{w} / \mathrm{v})$. The absorbance was read at $700 \mathrm{~nm}$ and the results were expressed as mmol TE/100 $\mathrm{g}$ of initial dried sample. 


\section{Iron chelation activity}

The chelation of ferrous ions by mint samples was estimated by comparison with ethylenediaminetetraacetic acid (EDTA) according to a modified version of the method described by $\mathrm{Wu}$ and $\mathrm{Ng}$ (2008). In short, 0.5 $\mathrm{mL}$ of sample or EDTA standard (25-300 $\mu \mathrm{M}$ in methanol) were mixed with $1.85 \mathrm{~mL}$ methanol and $0.05 \mathrm{~mL}$ $\mathrm{FeCl}_{2}(1.0 \mathrm{mM})$. Ferrozine $(0.1 \mathrm{~mL}$ of $5 \mathrm{mM})$ was added to the solution and the absorbance was read at $562 \mathrm{~nm}$ $10 \mathrm{~min}$ later. Samples were corrected against both a blank without sample and a sample blank without ferrozine; iron chelation activity was determined from an EDTA standard curve. Values were expressed as $\mu \mathrm{mol}$ EDTA equivalents per $100 \mathrm{~g}$ dried sample.

\section{Inhibition of cupric ion-induced human LDL cholesterol peroxidation}

The inhibitory activity of the mint samples against cupric ion-induced low density lipoprotein (LDL) cholesterol oxidation was determined according to the method outlined by Chandrasekara and Shahidi (2011) with slight modifications. Human LDL cholesterol (in PBS, pH 7.4, with 0.01\% EDTA) was dialyzed against $10 \mathrm{mM}$ PBS (pH 7.4, $0.15 \mathrm{M} \mathrm{NaCl})$ for $12 \mathrm{~h}$ under nitrogen at $4{ }^{\circ} \mathrm{C}$, and EDTA-free LDL was subsequently diluted to obtain standard protein concentration of $0.1 \mathrm{mg} / \mathrm{mL}$ with PBS. The Hasawi and Medina bound phenolics were not included in this assay because of their low activity. The soluble phenolics and aqueous infusion samples from Medina and Hasawi mint were diluted in 10 mM PBS to obtain a concentration of $0.1 \mathrm{mg}$ extract per $\mathrm{mL}$. The diluted LDL cholesterol $(0.5 \mathrm{~mL})$ was mixed with $100 \mu \mathrm{L}$ of the sample solution. Oxidation of LDL cholesterol was initiated by adding $400 \mu \mathrm{L}$ of $12.5 \mu \mathrm{M}$ cupric sulphate solution in distilled water. The mixture was mixed well and incubated at $37^{\circ} \mathrm{C}$ for $20 \mathrm{~h}$. The initial absorbance $(t=0)$ was read at $232 \mathrm{~nm}$ immediately after mixing and conjugated diene (CD) hydroperoxides formed at the end of the $20 \mathrm{~h}$ were measured. The corrected absorbance at $20 \mathrm{~h}$ against $0 \mathrm{~h}$ was employed to calculate the percentage inhibition of $\mathrm{CD}$ formation using the following equation: \% inhibition of $\mathrm{CD}$ formation $=\left(\mathrm{Abs}_{\text {oxidative }}-\mathrm{Abs}_{\text {sample }}\right) /\left(\mathrm{Abs}_{\text {oxidative }}-\mathrm{Abs}-\right.$ native) X 100, where $\mathrm{Abs}_{\text {oxidative }}=$ absorbance of $\mathrm{LDL}$ mixture and distilled water with $\mathrm{CuSO}_{4}$ only, $\mathrm{Abs}_{\text {sample }}=$ absorbance of LDL with extract and $\mathrm{CuSO}_{4}$, and $\mathrm{Abs}_{\text {na- }}$ tive $=$ absorbance of LDL with distilled water.

\section{Inhibition of thiobarbituric acid reactive substances (TBARS) formation in a cooked ground meat system}

To assess antioxidant effectiveness in food, the amount of TBARS, secondary products of lipid peroxidation, was measured in a meat model system over a two-week period. The shoulder meat used for this test was obtained fresh from a local supermarket. The fat content of the ground meat sample was $12.73 \pm 0.27 \%$, as determined according to the procedure of Bligh and Dyer (1959) as modified by Shahidi (2001). Briefly, $10 \mathrm{~g}$ of pork with $20 \%(\mathrm{w} / \mathrm{w})$ deionized water were homogenized using a Polytron PT 3000 (Brinkmann Instruments, Mississauga, ON, USA). Ten millilitres of chloroform and $20 \mathrm{~mL}$ of methanol were added and the mixture was homogenized for $2 \mathrm{~min}$. A further $10 \mathrm{~mL}$ portion of chloroform was added, followed by $30 \mathrm{~s}$ of homogenization, then $10 \mathrm{~mL}$ of deionized water were added, and the mixture was homogenized for $30 \mathrm{~s}$ again. The mixture was centrifuged at $1000 \mathrm{~g}$ for $10 \mathrm{~min}$, and then filtered using a Buchner funnel and Whatman no. 1 filter paper. The residue was re-extracted with chloroform, as above, and all filtrates were placed into a separatory funnel. The chloroform layer was collected and filtered through anhydrous sodium sulphate. The chloroform was evaporated from the lipids using a Rotavapor (Buchi, Flawil, Switzerland) while increasing heat and decreasing pressure until all the solvent was removed.

To determine the activity of mint samples for inhibiting TBARS formation, the method described by Shahidi and Alexander (1998) was followed with slight modifications. To prepare the meat model system, $80 \mathrm{~g}$ of freshly ground shoulder meat ( 5 days postmortem) were mixed with $20 \mathrm{~mL}$ of deionized water in a Mason jar. Test samples were added to the meat at a concentration of 200 ppm GAE (gallic acid equivalents), calculated from the values of the total phenolic content assay). A positive control was prepared by adding $200 \mathrm{ppm}$ of butylated hydroxyanisole (BHA) and a control was prepared without any antioxidant. Meat systems were thoroughly mixed and cooked in a water bath at $80^{\circ} \mathrm{C}$ for $30 \mathrm{~min}$ with occasional stirring. After cooling to room temperature, the samples were homogenized, transferred into plastic bags and stored at $4{ }^{\circ} \mathrm{C}$ until analysed for TBARS on days $0,2,5,7,10$, and 14 after preparation. Briefly, $2.0 \mathrm{~g}$ of each meat mixture were blended with $5.0 \mathrm{~mL}$ of $10 \%(\mathrm{w} / \mathrm{v})$ trichloroacetic acid (TCA). Then $5.0 \mathrm{~mL}$ of $0.02 \mathrm{M}$ 2-thiobarbituric acid (TBA) solution were added and the mixture was vortexed for $30 \mathrm{~s}$ and then centrifuged at $1000 \mathrm{~g}$ for $10 \mathrm{~min}$. The supernatant was filtered through a Whatman No. 3 filter paper and heated in a boiling water bath for $45 \mathrm{~min}$. The solution was cooled to room temperature and the absorbance was subsequently read at $532 \mathrm{~nm}$. A standard curve was prepared using 1,1,3,3-tetramethoxypropane $(1-6 \mu \mathrm{g} / \mathrm{mL})$ as malondialdehyde (MDA) precursor.

\section{Inhibition against peroxyl radical induced DNA scission}

The effectiveness of Medina and Hasawi mint against DNA scission was determined according to the method described by Chandrasekara and Shahidi (2011). DNA 
strand nicking was induced by peroxyl radical and examined with gel electrophoresis. The DNA was suspended in a buffer solution containing a mixture of Tris base, acetic acid and EDTA (TAE buffer; pH 8.5) at a concentration of $25 \mu \mathrm{g} / \mathrm{mL}$. A mixture containing $4 \mu \mathrm{L}$ of supercoiled pBR322 DNA, $4 \mu \mathrm{L}$ of $30 \mathrm{mM}$ AAPH, and $2 \mu \mathrm{L}$ of sample diluted in $10 \mathrm{mM}$ PBS were incubated at $37^{\circ} \mathrm{C}$ for $1 \mathrm{~h}$. A blank (without sample) and a control (without AAPH or sample) were also prepared. One microliter of loading dye (25\% bromophenol blue, $25 \%$ xylene cyanol, and $50 \%$ glycerol, w/v) was added to each mixture and the samples were loaded onto a $0.7 \%$ agarose gel with SYBR safe gel stain. Gel electrophoresis was run at $80 \mathrm{~V}$ for about $1.5 \mathrm{~h}$ and the bands were visualized under UV light. The intensity of the DNA bands was measured using the SpotDenso tool in Chemilmager software (Alpha Innotech Corporation, San Leandro, CA, USA). Antioxidant activity was expressed as a percentage of the DNA that remained intact to the DNA that was nicked normalized against the control.

\section{Inhibition of LPS stimulated COX-2 expression in J774A.1 mouse macrophage cells \\ Cell and cell culture condition}

The J774A.1 cells were obtained from American Type Culture Collection (ATCC, Menassas VA) and cultured in Dulbecco's Modified Eagle Medium (DMEM) with $10 \%$ fetal bovine serum and 1\% Amphotericin B/Streptomycin/Penicillin at $37^{\circ} \mathrm{C}$ and $5 \% \mathrm{CO}_{2}$. All experiments for J774A.1 were conducted in the same medium.

\section{mRNA isolation, CDNA synthesis and gene expression analysis}

To determine the mRNA expression levels in J774A.1 mouse macrophage, cells were cultured in 6 well plates (Costar, Corning Incorporated, Corning, NY, USA) overnight. J774A.1 cells were incubated in DMEM with 10\% fetal bovine serum and $1 \%$ antibiotic/antimycotic. Samples $(50,20$ and $5 \mu \mathrm{g} / \mathrm{mL}$ ) were used to treat the macrophages, and media were replaced every $24 \mathrm{~h}$. After $48 \mathrm{~h}$ incubation, for the control group, media were replaced, and for induction group, $10 \mathrm{ng} / \mathrm{mL}$ LPS was added into the media for inducing pro-inflammatory mediators (Huang et al. 2012). After $4 \mathrm{~h}$ induction, culture media was discarded and cells were collected according to the previously published protocol (Trasino et al. 2009). Briefly, cells were washed with $1 \times$ PBS twice and TRIzol reagent was added for total RNA isolation. StrataScript First Strand complementary DNA Synthesis kit was used to reverse transcribed complementary DNA. Inhibitory effect of mint samples on $C O X-2$ expression was examined by real-time PCR. Real-time PCR was performed on ABI Prism 7900HT Sequence Detection System using TaqMan Universal PCR Master Mix. The TaqMan gene expression assay for prostaglandin-endoperoxide synthase $2(C O X-2)$ was acquired from Applied Biosystems (Carlsbad, CA, USA) and used for gene detection. The mRNA amounts were normalized to an internal control, TATA-binding protein (TBP) mRNA. The following amplification parameters were used for PCR: $50^{\circ} \mathrm{C}$ for 2 min, $95^{\circ} \mathrm{C}$ for $10 \mathrm{~min}$, and 46 cycles of amplification at $95^{\circ} \mathrm{C}$ for $15 \mathrm{~s}$ and $60^{\circ} \mathrm{C}$ for $1 \mathrm{~min}$.

\section{Determination of major phenolic compounds by HPLC/ESI-MS/MS}

Reversed phase high performance liquid chromatography with tandem mass spectrometry was used to determine the major phenolic compounds present in the mint samples. A slightly modified version of the method outlined by Zheng and Wang (2001) was used. Briefly, samples were prepared by dissolving $0.02 \mathrm{~g}$ extract in $2.0 \mathrm{~mL}$ of $50 \%$ HPLC-grade methanol and passed through a $0.45-\mu \mathrm{m}$ filter before injection into a reverse phase C18 column $(250 \mathrm{~mm}$ length, $4.6 \mathrm{~mm}$ i.d., $5 \mu \mathrm{m}$ particle size, Sigma-Aldrich Canada Ltd. (Oakville, ON, Canada) with a guard column. The mobile phase was acetonitrile (A) and acidified water containing $2.5 \%$ formic acid (B). The gradient was as follows: $0 \mathrm{~min}, 5 \% \mathrm{~A}$; $10 \mathrm{~min}, 15 \%$ A; $30 \mathrm{~min}, 25 \%$ A; $35 \mathrm{~min}, 30 \%$ A; $50 \mathrm{~min}$, $55 \%$ A; $55 \mathrm{~min}, 90 \%$ A; $57 \mathrm{~min}, 100 \% \mathrm{~A}$ and then held for $10 \mathrm{~min}$ before returning to the initial conditions. The flow rate was $1.0 \mathrm{~mL} / \mathrm{min}$ and the wavelengths of detection were 280,350 , and $380 \mathrm{~nm}$. LC flow was analyzed online by a mass selective detector system (LC-MSDTrap-SL, Agilent) in electrospray ionization (ESI) mode. An external standard method using authentic compounds was used to confirm the identified compounds.

\section{Statistical analysis}

All statistical analysis was completed with Sigmastat for Windows version 2.0 (Jandel Corp., San Rafael, CA, USA). All analyses were completed in triplicate and values are expressed as the mean \pm standard deviation (SD). Two-way analysis of variance (ANOVA), with Tukey's Honestly Significant Differences (HSD) test, was conducted for the TBARS assay and one-way ANOVA with pairwise comparisons and Tukey's test was completed for all other assays. Differences were considered significant at the $p<0.05$ level.

\section{Results and discussion}

\section{Extraction and dechlorophyllization of soluble phenolics}

The yields of soluble extracts of Medina and Hasawi mint were 38.11 and $27.94 \%$, respectively. The yields from the dechlorophyllization of these soluble extracts were $85.43 \%$ for Medina mint and $95.92 \%$ for Hasawi mint. 
Chlorophyll serves as a photosensitizer and is known to render prooxidant activity (Choe \& Min 2006), thus it was removed from the extract to prevent interference in the antioxidant tests. The efficiency of the dechlorophyllization method was tested by measuring the reduction of absorbance at $660 \mathrm{~nm}$ and confirmed using HPLC analysis which showed the successful removal of chlorophyll without affecting the phenolic composition of the extract (data not shown). In all antioxidant tests, the dechlorophyllized soluble phenolics extract from Medina mint had a higher antioxidant activity than the sample that was not dechlorophyllized (Table 1). Although the values between the two samples were always very close, the difference was usually statistically significant, indicating that there was a benefit in removing chlorophyll prior to measuring antioxidant activity.

\section{Total phenolic content}

The total phenolic content of mint samples was determined according to the Folin-Ciocalteau's reagent assay and the results are reported in Table 1. The total phenolic content in the soluble fraction of Medina mint was $109.98 \mathrm{mg} \mathrm{GAE} / \mathrm{g}$ initial dried sample and $2.64 \mathrm{mg} \mathrm{GAE} / \mathrm{g}$ dried sample in the insolublebound fraction. For Hasawi mint, the total phenolic content was 36.80 and $1.54 \mathrm{mg}$ GAE/g sample for the soluble and bound fractions, respectively. The total phenolic content of the non-dechlorophyllized soluble Medina mint sample was $92.26 \mathrm{mg}$ GAE/g sample, slightly less than that for the dechlorophyllized sample. Similarly, the total phenolic content was 53.22 and 23.99 mg GAE/g sample for the Medina and Hasawi mint aqueous infusions, respectively. There was a much higher phenolic content in the soluble fractions than the bound fractions for both the Medina and Hasawi mint samples. For all three sample forms, Medina mint had a higher total phenolic content. There was a significant $(p \leq 0.05)$ difference between phenolic content in the solvent soluble and aqueous infusion forms of both samples, but the difference between the bound phenolic content of both samples was not significant $(p>0.05)$.

The results for the soluble phenolics extract and bound phenolics extract did not agree with some previously published results, however, a very different extraction technique was employed in those studies (Atoui et al. 2005; Zheng \& Wang 2001). For example, analysis of the total phenolic content from the methanolic fraction of mint yields results that are about 100 times lower than those obtained for the soluble or insoluble-bound phenolics extracts used in this study (Atanassova and Georgieva 2010). However, in a study that analyzed the aqueous infusion of spearmint, the value for total phenolics was $35.3 \mathrm{mg}$ GAE/g dry sample weight which is approximately in between the values obtained for Medina and Hasawi mint samples (Atoui et al. 2005). Another study also found agreeable results for the aqueous mint infusions (Dorman et al. 2003). It seems likely that any disagreements in value for total phenolics may originate from the different geographical origins, agro-climatic (climatic, seasonal and geographical) variations, extraction procedures and physiological conditions of the plants (Cavaliere 2009; Tahira et al. 2011). Ravn et al. (1994) reported higher levels of rosmarinic and caffeic acids during spring than summer and winter, and noted a loss of polyphenols during sample preparation.

Table 1 Phenolic contents and Antioxidant activities of Medina and Hasawi mint ${ }^{1}$

\begin{tabular}{|c|c|c|c|c|c|c|c|}
\hline \multirow{3}{*}{$\begin{array}{l}\text { Phenolic contents and } \\
\text { Antioxidant activities }\end{array}$} & \multicolumn{7}{|l|}{ Sample } \\
\hline & \multicolumn{4}{|l|}{ Medina mint } & \multicolumn{3}{|l|}{ Hasawi mint } \\
\hline & Soluble & Bound & $\begin{array}{l}\text { Aqueous } \\
\text { infusion }\end{array}$ & $\begin{array}{l}\text { Soluble - not } \\
\text { dechlorophyllized }\end{array}$ & Soluble & Bound & $\begin{array}{l}\text { Aqueous } \\
\text { infusion }\end{array}$ \\
\hline $\begin{array}{l}\text { Total phenolics (mg GAE/g } \\
\text { sample) }\end{array}$ & $109.98 \pm 5.80^{a}$ & $2.64 \pm 0.11^{d}$ & $53.22 \pm 5.35^{\mathrm{e}}$ & $92.26 \pm 3.71^{c}$ & $36.80 \pm 1.39^{b}$ & $1.54 \pm 0.08^{d}$ & $\begin{array}{l}23.99 \pm \\
3.22^{f}\end{array}$ \\
\hline \multicolumn{8}{|c|}{ Antioxidant activity assays (mmol TE/100 g sample) } \\
\hline DPPH & $108.75 \pm 25.07^{a}$ & $0.72 \pm 0.04^{d}$ & $87.35 \pm 16.18^{\mathrm{ab}}$ & $95.73 \pm 29.08^{\mathrm{ac}}$ & $60.90 \pm 16.14^{b c}$ & $0.12 \pm 0.03^{d}$ & $\begin{array}{l}33.99 \pm \\
1.92 b^{c d}\end{array}$ \\
\hline ORAC & $5087 \pm 176.0^{\mathrm{a}}$ & $9.348 \pm 1.06^{d}$ & $1563 \pm 988.0^{\mathrm{bc}}$ & $4672 \pm 420.0^{a}$ & $2663 \pm 76.0^{c}$ & $6.000 \pm 0.58^{d}$ & $\begin{array}{l}867 \pm \\
696.0^{\mathrm{bd}}\end{array}$ \\
\hline TEAC & $9849 \pm 291.0^{\mathrm{a}}$ & $25.85 \pm 0.84^{b}$ & $5343 \pm 103.0^{c}$ & $7682 \pm 68.0^{d}$ & $3743 \pm 317.0^{\mathrm{e}}$ & $20.31 \pm 0.84^{b}$ & $\begin{array}{l}2260 \pm \\
169.0^{f}\end{array}$ \\
\hline Reducing Power & $1692 \pm 22.0^{a}$ & $4.50 \pm 0.08^{b}$ & $108.0 \pm 6.4^{c}$ & $1571 \pm 46.0^{d}$ & $478.4 \pm 2.2^{e}$ & $2.05 \pm 0.29^{b}$ & $54.7 \pm 1.2^{b c}$ \\
\hline $\begin{array}{l}\text { Iron (II) chelation ( } \mu \text { mol EDTA } \\
\text { eq/100 g sample) }\end{array}$ & $562 \pm 30.0^{a}$ & $0.316 \pm 0.003^{c}$ & $1006 \pm 30.0^{d}$ & $553 \pm 5.0^{a}$ & $425 \pm 10.0^{b}$ & $0.311 \pm 0.007^{c}$ & $\begin{array}{l}1056 \pm \\
50.0^{\mathrm{d}}\end{array}$ \\
\hline
\end{tabular}

${ }^{1}$ Data are expressed as the mean \pm SD $(n=3)$. Values with the same letter (a to $f$ ), in the same row, are not significantly different (Tukey test, $\left.p>0.05\right)$. GAE, gallic acid equivalents; and TE, trolox equivalents 


\section{Radical scavenging-based antioxidant activity assays}

The antioxidant activity of the two mint species was determined by different tests based on radical scavenging capacity, chelating activity and reducing power of the extracts. These tests followed different mechanisms of antioxidant action and can provide valuable information when analyzed collectively. Some methods of antioxidant action include scavenging of radicals by being oxidized themselves to produce less reactive radicals, singlet oxygen quenching, metal chelation, quenching secondary oxidation products, and inhibiting pro-oxidative enzymes, among other mechanisms (Shahidi and Zhong 2010). There are two main mechanisms by which antioxidants can scavenge free radicals, hydrogen atom transfer (HAT) and single electron transfer (SET), however, very few reactions exclusively follow one or the other (Prior et al. 2005). From the antioxidant activity assays used in this study that measure free radical scavenging the only ones that are believed to occur exclusively by HAT are ORAC and DNA scission. Reducing power measures antioxidant activity by following a SET mechanism and DPPH scavenging and TEAC follow a mix of both HAT and SET. The iron chelating activity assay measures the sample's capacity to chelate ferrous ion and, since the TBARS assay measures secondary oxidation products, it indicates the total antioxidant activity. The LDL cholesterol oxidation assay works by utilizing metal-ion chelating or peroxyl radical scavenging activity, or more likely, a combination of both. The following section will only discuss TEAC, DPPH radical scavenging, ORAC, reducing power and iron chelating activities of the extract as shown in Table 3. Results for antioxidant activity tests conducted in biological and food systems are discussed in sections 3.4, 3.5 and 3.6.

TEAC values ranged from 25.85 and $20.31 \mathrm{mmol} \mathrm{TE} /$ $100 \mathrm{~g}$ sample for the Medina and Hasawi bound phenolics to 9849 and $3743 \mathrm{mmol} \mathrm{TE} / 100 \mathrm{~g}$ sample for their soluble counterparts, respectively. The antioxidant activity of the aqueous infusions was relatively high at 5343 and $2260 \mathrm{mmol} \mathrm{TE} / 100 \mathrm{~g}$ sample for the Medina and Hasawi mints, respectively. The activity of the nondechlorophyllized Medina soluble phenolics was slightly, but significantly $(p \leq 0.05)$, less than that of the dechlorophyllized sample (Table 1 ). The antioxidant activity, as measured by the ORAC assay followed the same trend as those for other antioxidant activity assays (Table 1). Medina mint soluble phenolics had the highest activity at $5087 \mathrm{mmol} \mathrm{TE} / 100 \mathrm{~g}$ sample, followed by its nondechlorophyllized counterpart with an activity of 4672 mmol TE/100 g sample, and then by the aqueous Medina and Hasawi mint infusions. The bound phenolics had the least activity. Due to the high variability between replicate samples, no statistically significant differences $(p>0.05)$ were observed in this assay. The reducing power assay also followed the same trend as the other radical scavenging assays, as reported in Table 1. One notable difference to the trend is that the Hasawi mint soluble extract had a higher antioxidant value than the Medina mint aqueous infusion in this assay.

The DPPH radical scavenging activity assay showed a slight difference in the trend of antioxidant activity with other assays; the aqueous infusion of Medina mint had a higher antioxidant activity $(87.35 \mathrm{mmol} \mathrm{TE} / 100 \mathrm{~g}$ sample) than the Hasawi soluble phenolics $(60.90 \mathrm{mmol} \mathrm{TE} /$ $100 \mathrm{~g}$ sample). The decreasing order of the activity of other samples was Medina soluble phenolics > nondechlorophyllized Medina mint soluble phenolics > Hasawi mint aqueous infusion > Medina mint bound phenolics > Hasawi mint bound phenolics. As per the trend for the other assays, the antioxidant activity of the Medina mint phenolics in each sample fraction was higher than the Hasawi mint sample counterpart (Table 1). Furthermore, the iron chelation activity, expressed as $\mu \mathrm{mol}$ EDTA/100 g sample, indicated very strong activity of the aqueous infusion of mint samples which was higher than that of the soluble phenolic extracts of the mint samples. Additionally, the aqueous infusion of Hasawi mint showed a greater iron chelating activity than the aqueous infusion of Medina mint, although not significantly $(\mathrm{p}>0.05)$ different (Table 1).

The results for total phenolic content are usually a good indicator of the antioxidant activity. There was a clear relationship between the total phenolic content and the antioxidant activity; samples with the higher phenolic content were more effective antioxidants, especially in the tests that measured free radical scavenging. It is clear that the Medina mints showed a significantly stronger antioxidant activity than the Hasawi mints in all assays, except for the iron chelating activity assay. Of the different sample forms, the soluble phenolics extract typically had the highest antioxidant activity and the bound phenolics extract had the lowest. One exception was in the iron chelating activity assay where the aqueous infusions showed a significantly higher activity than the soluble or bound phenolics. An explanation for the difference in the trend may be that the phenolic components within each extract do not possess the optimum structural characteristics for metal chelation (Hider et al. 2001). The aqueous infusions underwent no further purification than being passed through a Whatman no. 1 filter paper $(11 \mu \mathrm{m}$ pore size), therefore it is likely that proteins are present in these samples and thus may bind the iron and interfere in the assay. Iron chelation activity for the purified phenolic extracts seems to be directly related to the total phenolic content; the values for Medina mint were still higher than those for Hasawi mint and the soluble 
phenolics extracts were still higher than the bound phenolics extracts. From the data prestented, it can be concluded that Mentha extracts may be able to afford protection against oxidative damage by removing iron (II) ions which may otherwise participate in hydroxyl radical-generating Fenton-type reactions or in metal-catalyzed hydroperoxide decomposition reactions if available in a free unsequestered form (Dorman et al. 2003).

\section{Inhibition of cupric ion-induced human LDL-cholesterol oxidation}

Free radical induced or metal ion dependent oxidation of LDL cholesterol is an important step in developing atherosclerotic lesions that lead to coronary heart diseases (Halliwell 1997). Dietary antioxidants that inhibit LDL oxidation may thus help reducing the occurrence of coronary heart diseases. The antioxidant activity of mint extracts was determined by measuring the concentration of conjugated dienes formed during coppercatalyzed human LDL cholesterol oxidation in vitro, and the results were expressed as percentage inhibition of oxidation based on the $\mathrm{CD}$ value after $20 \mathrm{~h}$ incubation (Table 2). The aqueous infusion of Medina mint showed the highest inhibition of $77.90 \%$, followed by soluble extract of Medina mint (72.62\%), then soluble extract of Hasawi mint (21.06\%) and subsequently the aqueous infusion of Hasawi mint (20.75\%). However, there was no significant $(p>0.05)$ difference between the inhibition percentage of the solvent soluble phenolics and aqueous infusion of each mint variety. The mechanism by which phenolics in mint extracts inhibit LDL cholesterol oxidation may be a combined effect of chelation of cupric ions (which catalyzes the oxidation) as well as scavenging of peroxyl radicals formed. It is interesting that the aqueous infusion showed lower antioxidant activity than the soluble phenolics in all the antioxidant assays employed, except for iron chelation and inhibition of LDL cholesterol oxidation. The better ability of the phenolics in the aqueous infusion to chelate ferric ions may also partly prove them to be better chelators of cupric ions, thus exhibiting higher copper-induced LDL cholesterol oxidation inhibition. There is a possibility that

Table 2 Inhibition of LDL cholesterol oxidation in the presence of mint extracts ${ }^{1}$

\begin{tabular}{ll}
\hline Samples & Inhibition (\%) \\
\hline Hasawi mint soluble phenolics & $21.06 \pm 1.53^{\mathrm{a}}$ \\
Medina mint soluble phenolics & $72.62 \pm 1.86^{\mathrm{b}}$ \\
Hasawi mint aqueous infusion & $20.75 \pm 1.82^{\mathrm{a}}$ \\
Medina Mint aqueous infusion & $77.90 \pm 3.61^{\mathrm{b}}$ \\
\hline
\end{tabular}

'Data are expressed as the mean \pm SD $(n=3)$. Values with the same letter $(a, b)$, in the same column, are not significantly different (Tukey test, $p>0.05$ ). GAE, gallic acid equivalents; and TE, Trolox equivalents phenolic compounds at high concentrations may complex with protein moieties of the LDL cholesterol molecules, which makes them unavailable to inhibit oxidation of cholesterol. Several earlier studies have shown that phenolic compounds can inhibit protein oxidation by virtue of binding to them and forming complexes with the protein molecues (Siebert et al. 1996; Riedl and Hagerman 2001).

\section{Inhibition of thiobarbituric acid reactive substances (TBARS) formation}

The TBARS formation in the cooked meat model system, summarized in Table 3, showed a variation from the trend in other antioxidant assays. On day 14, the order of increasing TBARS formation inhibition, expressed as mg of MDA equivalents $/ \mathrm{kg}$ meat, was aqueous infusion of Medina mint (4.49), soluble phenolics of Hasawi mint (3.30), soluble phenolics of Medina mint (1.89), soluble phenolics of nondechlorophyllized Medina mint (1.43), and aqueous infusion of Hasawi mint (1.39). In other words, aqueous infusion of Medina mint had the lowest antioxidant activity in this assay and aqueous infusion of Hasawi mint had the highest activity. On all days tested, the control (no antioxidant) had significantly $(p<0.05)$ higher values than the other test samples indicating that the added mint extracts did have an antioxidant effect. In addition, BHA consistently afforded the lowest TBARS values after day 0 but there was not always a statistically significant $(\mathrm{p}<0.05)$ difference between this value and the samples. The order of antioxidant activity between the samples varied on each day they were tested, however, all samples, except aqueous infusion of Hasawi mint, were relatively steady after day 7 .

The inhibition of oxidation in a meat model system was measured to determine the effectiveness of mint samples in preventing quality deterioration in muscle foods. The lipids in processed foods are characterized by a high surface-to-volume ratio and these foods typically require larger amounts and different types of antioxidants (Zhong and Shahidi, 2012). Other experiments have shown the antioxidant activity of mint in meat model systems (Azam et al. 2004; Politeo et al. 2006), however, this is the first with solvent extracted polyphenols and not with only the aqueous extracts or mint oil. The antioxidant activity on day 14 , the final day of experiment, did not follow the trend of the other antioxidant activity tests. Aqueous infusion of Medina mint had the lowest activity followed by soluble phenolics of Hasawi mint. Among the other three samples tested, soluble phenolics of Medina mint (dechlorophyllized and non-dechlorophyllized) and aqueous infusion of Hasawi mint, were not statistically different from each 
Table 3 Antioxidant activity of mint extracts determined through the measurement of TBARS in a cooked meat system ${ }^{1}$

\begin{tabular}{|c|c|c|c|c|c|c|c|}
\hline \multirow[t]{2}{*}{ Samples added to pork } & \multirow{2}{*}{$\begin{array}{l}\text { Sample } \\
\text { concentration } \\
\text { (mg /g pork) }\end{array}$} & \multicolumn{6}{|c|}{ TBARS (mg MDA equivalents/kg meat) } \\
\hline & & Day 0 & Day 2 & Day 5 & Day 7 & Day 10 & Day 14 \\
\hline Control & - & $3.84 \pm 1.31^{\mathrm{a} 1}$ & $4.61 \pm 0.11^{\mathrm{ab} 1}$ & $4.75 \pm 0.11^{\mathrm{bcl}}$ & $4.34 \pm 0.09^{\mathrm{ab} 1}$ & $4.71 \pm 0.25^{b 1}$ & $5.53 \pm 0.11^{c 1}$ \\
\hline BHA & 0.25 & $1.07 \pm 0.13^{\mathrm{a} 23}$ & $1.02 \pm 0.04^{\mathrm{a} 2}$ & $0.73 \pm 0.04^{\mathrm{a} 2}$ & $0.57 \pm 0.04^{\mathrm{a} 2}$ & $0.76 \pm 0.04^{\mathrm{a} 2}$ & $0.83 \pm 0.02^{\mathrm{a} 2}$ \\
\hline Medina mint - soluble extract & 1.73 & $0.88 \pm 0.08^{\mathrm{a} 2}$ & $1.06 \pm 0.07^{\mathrm{a} 2}$ & $1.46 \pm 0.08^{\mathrm{ab} 23}$ & $1.37 \pm 0.05^{\mathrm{ab} 23}$ & $2.05 \pm 0.04^{\mathrm{b} 3}$ & $1.89 \pm 0.08^{\mathrm{b} 3}$ \\
\hline $\begin{array}{l}\text { Medina mint - soluble extract, not } \\
\text { dechlorophyllized }\end{array}$ & 2.07 & $0.75 \pm 0.08^{\mathrm{a} 2}$ & $1.04 \pm 0.02^{\mathrm{ab} 2}$ & $1.44 \pm 0.02^{\mathrm{ab} 23}$ & $1.76 \pm 0.14^{\mathrm{b} 3}$ & $1.58 \pm 0.16^{\mathrm{b} 3}$ & $1.43 \pm 0.04^{\mathrm{ab} 23}$ \\
\hline Medina mint - aqueous infusion & 9.4 & $1.84 \pm 1.56^{\mathrm{a} 3}$ & $1.36 \pm 0.11^{\mathrm{ab} 3}$ & $1.80 \pm 0.03^{\mathrm{ab} 34}$ & $1.03 \pm 0.02^{\mathrm{b} 23}$ & $3.43 \pm 0.04^{\complement 4}$ & $4.49 \pm 0.08^{\mathrm{d} 4}$ \\
\hline Hasawi mint - soluble extract & 3.8 & $0.81 \pm 0.12^{\mathrm{a} 2}$ & $2.52 \pm 0.09^{\mathrm{bd} 4}$ & $2.50 \pm 0.01^{\mathrm{b} 45}$ & $3.27 \pm 0.06^{\mathrm{bc} 4}$ & $3.67 \pm 0.11^{c 4}$ & $3.30 \pm 0.18^{\mathrm{cd} 5}$ \\
\hline Hasawi mint - aqueous infusion & 22.57 & $0.69 \pm 0.01^{\mathrm{a} 2}$ & $2.38 \pm 0.11^{b c 24}$ & $2.94 \pm 0.16^{\mathrm{b} 5}$ & $2.57 \pm 0.02^{\mathrm{bc} 4}$ & $1.95 \pm 0.02^{\mathrm{cd} 3}$ & $1.39 \pm 0.11^{\mathrm{ad} 23}$ \\
\hline
\end{tabular}

${ }^{1}$ Data are expressed as mean \pm SD $(n=3)$. Values with the same letter (a to d), in the same row are not significantly different $(p>0.05)$. Values with the same superscript number ( 1 to 5$)$, in the same column are not significantly different $(P>0.05)$. The concentration of sample as mg/g pork is equivalent to 200 ppm gallic acid equivalents calculated from total phenolic content. Abbreviations are: MDA, malondialdehyde; and BHA, butylated hydroxyanisole

other, but were still more effective than the blank. These results may be due to the further breakdown of oxidation products after day 5 . For example, after 3 to 5 days of storage, hexanal, a major breakdown product of linoleic acid, begins to decline perhaps due to its further oxidation or interaction with other meat components (Shahidi and Alexander 1998). In fact, up to day 5 the antioxidant activity of samples followed the expected trend; soluble phenolics of Medina mint (both crude and dechlorophyllized) exhibited the greatest activity followed by aqueous infusion of Medina mint, soluble phenolics of Hasawi mint, and aqueous infusion of Hasawi mint.

\section{Inhibition against peroxyl radical induced DNA scission}

The supercoiled plasmid DNA strand inhibition assay measures the effectiveness of the samples in preventing DNA strand scission by peroxyl radicals. Results for the inhibition of DNA scission are presented in Figs. 1 and 2. The inhibition of DNA scission mostly followed the expected trend. Non-dechlorophyllized Medina mint soluble phenolics had the highest activity with $78.35 \%$ inhibition, followed by soluble phenolics of dechlorophyllized Medina and Hasawi mints with 76.42 and $46.69 \%$ inhibition, respectively, and then aqueous infusion of Hasawi and Medina mints with 18.04 and $11.85 \%$ inhibition, respectively, and subsequently bound phenolics of Hasawi and Medina mints with 0.17 and $0.16 \%$ inhibition, respectively. The blank (DNA and AAPH only) showed no inhibition, but the control (DNA only) showed about $10 \%$ nicked DNA. The Medina and Hasawi bound phenolics, the aqueous samples, and the blank all had linear DNA bands indicating that the DNA was nicked twice. Previous studies have also found Mentha extracts to be antimutagenic as it could enhance error-free repair for DNA damage (VokovicGacis and Simic 1993).

In this assay the bound phenolics extracts exhibited a higher inhibition than the aqueous infusions. Once again, this may be due to other components present in the aqueous infusions that have been removed from the purified bound phenolics extract. Often, the difference between an antioxidant and a pro-oxidant is a matter of concentration and conditions. It is possible that, under these conditions, some of the compounds in the aqueous infusion samples are acting as prooxidants and stimulating DNA scission instead of inhibiting it. Azam et al. (2004) demonstrated the prooxidant activity of polyphenolic compounds in DNA scission under similar conditions to those employed in this study. The linear

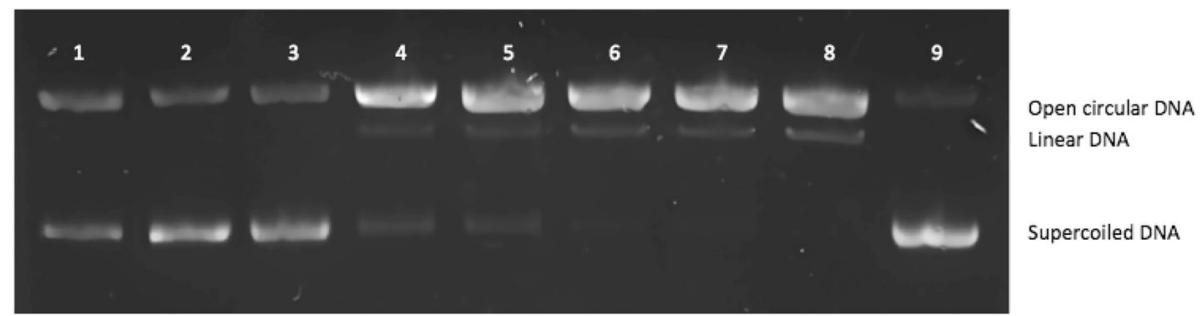

Fig. 1 Peroxyl radical induced DNA scission gels in the presence of Medina and Hasawi mint samples. Lane 1: Hasawi mint soluble extract (0.048 $\mathrm{g} / \mathrm{mL})$; Lane 2: Medina mint soluble extract $(0.035 \mathrm{~g} / \mathrm{mL})$; Lane 3: Medina mint soluble extract, not dechlorophyllized $(0.035 \mathrm{~g} / \mathrm{mL})$; Lane 4: Medina mint bound extract $(2.67 \mathrm{~g} / \mathrm{mL})$; Lane 5: Hasawi mint bound extract $(2.68 \mathrm{~g} / \mathrm{mL})$; Lane 6: Hasawi mint aqueous infusion $(0.013 \mathrm{~g} / \mathrm{mL})$; Lane 7 : Medina mint aqueous infusion (0.013 g/mL); Lane 8: Blank (DNA and AAPH only); and Lane 9: Control (DNA only) 


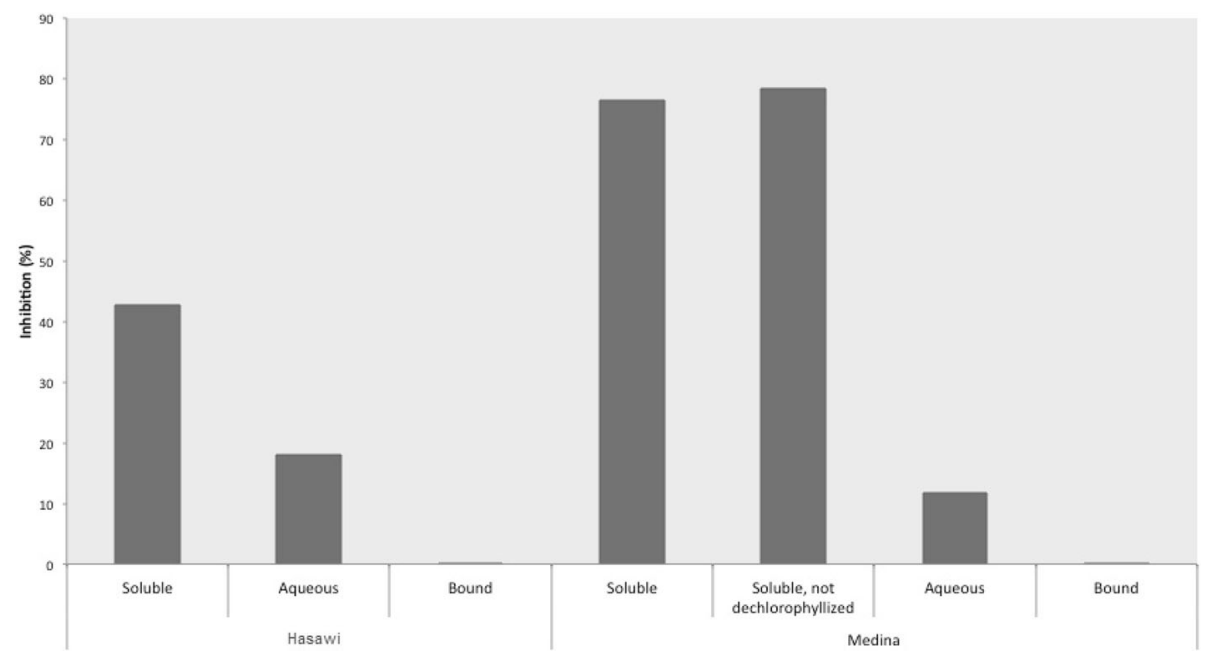

Fig. 2 Percentage inhibition of DNA scission by Medina and Hasawi mint. Percent inhibition was determined from the normalized ratio of supercoiled to open circular DNA for each sample. DNA scission was induced by peroxyl radical (AAPH at a final concentration of $12 \mathrm{mM}$ ) and kept at $37^{\circ} \mathrm{C}$ for $1 \mathrm{~h}$

DNA band on the electrophoresis gel indicates the presence of double strand scission in the bound and aqueous samples, as well as the blank. The exact reason for the increased activity of the bound phenolics is unknown, but clearly there are other mechanisms operating here than just peroxyl radical scavenging since the relative activity differs from the ORAC results.

\section{Inhibition of LPS stimulated COX-2 expression in J774A.1 mouse macrophage cells}

The mRNA expression of the inflammatory mediator, cyclooxygenase-2 (COX-2) was monitored in order to test the involvement of transcriptional events during their biosynthesis. Medina and Hasawi mint extracts were tested for their inhibitory effect on LPS-stimulated expression of COX-2 in mouse macrophage J774A.1 cells. Before the anti-inflammatory assay, cytotoxicity of samples was examined. Medina and Hasawi mint extracts did not affect the cells at any concentration. In Fig. 3, negative control indicate COX-2 expression level without LPS stimulation and positive control was measured after $10 \mathrm{ng} / \mathrm{mL}$ LPS stimulation for $4 \mathrm{~h}$. It is clear that macrophages treated with LPS alone had the highest levels of $C O X-2$ mRNA, which were lowered by the addition of mint extracts. Samples at 50, 20 and $5 \mu \mathrm{g} / \mathrm{mL}$ were used to treat the macrophages for $48 \mathrm{~h}$

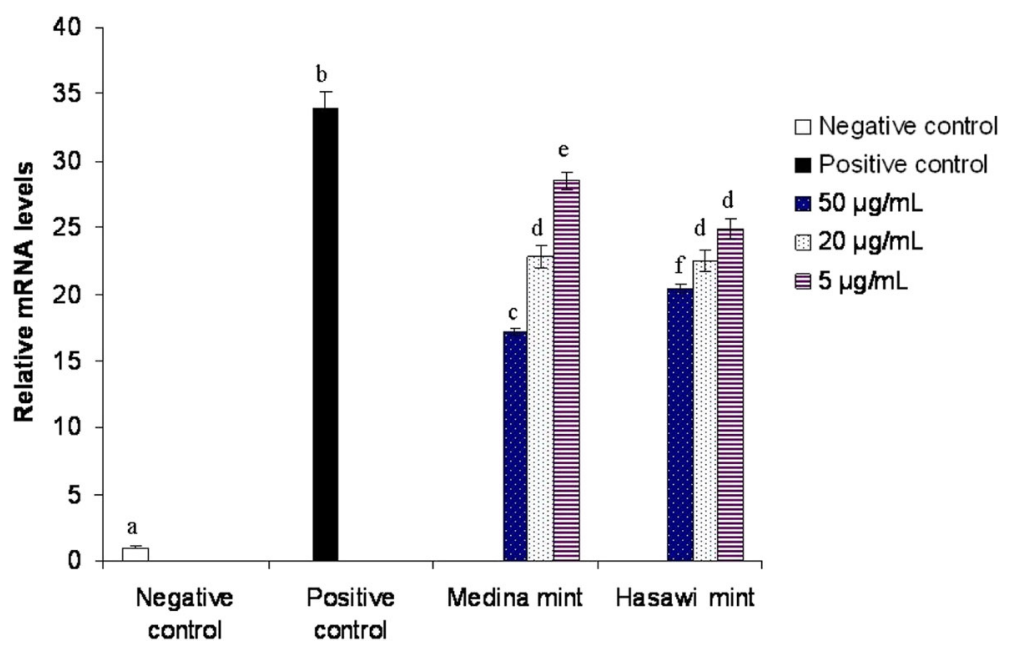

Fig. 3 Inhibitory effect of mint extracts on LPS stimulated COX-2 expression in J774A.1 mouse macrophage cells. Cells were pretreated with samples for $48 \mathrm{~h}$ prior to LPS induction, after $4 \mathrm{~h}$ of induction, RNA was isolated and COX-2 expression was examined. Negative control indicate COX-2 expression level without LPS stimulation and positive control was measured after $10 \mathrm{ng} / \mathrm{mL}$ LPS stimulation for $4 \mathrm{~h}$ 
Table 4 Major phenolic compounds in mint identified using HPLC/ESI-MS/MS

\begin{tabular}{|c|c|c|c|c|c|}
\hline Peak No. & Phenolic compound & Retention time (min) & {$[\mathrm{M}-\mathrm{H}]^{-}$} & Fragments & Detected in soluble extracts of \\
\hline 1 & Caffeoylquinic acid 3.3 & $377[\mathrm{M}-\mathrm{H}+\mathrm{Na}]^{-}$ & 179,191 & Medina mint ${ }^{A, B}$, Hasawi mint ${ }^{A, B}$ & \\
\hline 2 & Salvianic acid & 6.7 & 197, $395[2 \mathrm{M}-\mathrm{H}]^{-}$ & 179 & Medina mint ${ }^{A, B}$ \\
\hline 3 & Rosmarinic acid & 27.9 & 359 & $161,179,197$ & Medina mint ${ }^{A, B}$, Hasawi mint ${ }^{A, B}$ \\
\hline 4 & Luteolin & 36.6 & 285 & 151,107 & Medina mint $t^{A, B}$ \\
\hline 5 & Salvigenin & 38.8 & 327 & 313,165 & Medina mint ${ }^{A, B}$, Hasawi mint ${ }^{A, B}$ \\
\hline 6 & Chrysoeriol & 39.6 & 299 & 284 & Medina mint ${ }^{A}$, Hasawi mint ${ }^{A}$ \\
\hline 7 & Thymonin & 40.4 & 359 & $283,185,147$ & Medina mint ${ }^{A, B}$, Hasawi mint ${ }^{A, B}$ \\
\hline 8 & Carnosol & 42.3 & 329 & $301,201,229$ & Medina mint ${ }^{A, B}$, Hasawi mint ${ }^{A, B}$ \\
\hline
\end{tabular}

$1 \mathrm{~A}$, not dechlorophyllized samples and $\mathrm{B}$, dechlorophyllized samples

prior to LPS induction. Both samples significantly inhibited mRNA level of $C O X-2$ at concentrations as low as $5 \mu \mathrm{g} / \mathrm{mL}$ (Fig. 3) and a concentration dependent inhibitory effect was observed, with the most potent inhibitory effect being for Medina mint extracts at $50 \mu \mathrm{g} / \mathrm{mL}$. The level of COX-2 mRNA was reduced by 49.5 and $39.8 \%$ in Medina and Hasawi mint extract $(50 \mu \mathrm{g} / \mathrm{mL})$ treated macrophages, respectively. However, there were no significant differences among the effect on extracts of Medina mint at $20 \mu \mathrm{g} / \mathrm{mL}$ and Hasawi mint at 20 and $5 \mu \mathrm{g} / \mathrm{mL}$.
Cyclooxygenase-2 (COX-2)-catalysed synthesis of prostaglandin E2 plays a key role in inflammation and its associated diseases, such as cancer and cardiovascular disease (O'Leary et al. 2004; Shahidi and Zhong 2009; Zhong et al. 2012). There are numerous reports demonstrating that flavonoids inhibit COX-2 activity (Liang et al. 2001; Raso 2001). However, transcriptional regulation of $C O X-2$ can also be important. The effect of mint extracts on COX-2 mRNA expression suggests the involvement of a pretranslational or transcriptional

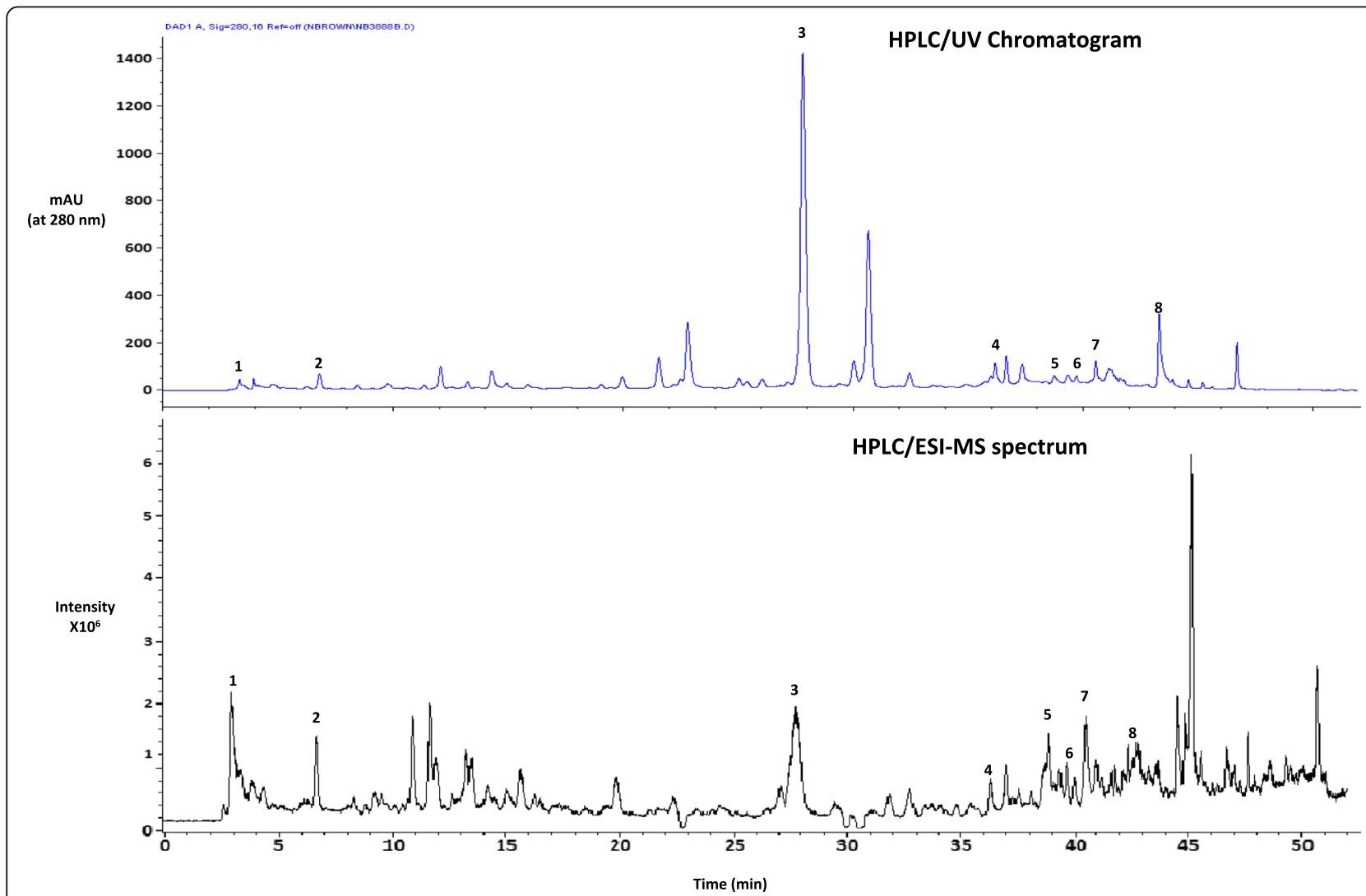

Fig. $4 \mathrm{HPLC/DAD}$ chromatogram and HPLC/ESI-MS spectrum of the soluble phenolic components in non-dechlorophyllized Medina mint. Peak identities are numbered in Table 3.4 
mechanism in the inhibition of $\mathrm{COX}-2$ protein production. The polyphenols in the mint extracts may be the main inhibitors of $\mathrm{COX}-2$ activity. Compared to steroidal and non-steroidal chemical drugs for treating inflammation, naturally derived substances are readily available at lower costs with limited side effects and intolerance (Zhong et al. 2012) and it is clear from the above data that mint can serve as a natural source of antiinflammatory substances.

\section{Identification of the major phenolic acids present in mint} samples by HPLC/ESI-MS/MS

The major phenolic compounds in the soluble phenolic extracts of mint samples were identified on the basis of their retention times, absorbance spectra, and ESI-MS fragmentation pattern which were compared to previously published studies (Plazonic et al. 2009) (Table 4). Figure 4 shows the identified peaks in the HPLC/DAD and ESI-MS chromatogram An example for fragmentation of rosmarinic acid is given in Fig. 5.
Phenolic acids and flavonoids identified in the mint samples were caffeic, salvianic, and rosmarinic acids, luteolin, salvigenin, chrysoeriol, thymonin, and carnosol. Rosmarinic acid was the most abundant phenolic compound in all mint samples, determined from the peak areas (peak no. 3 in Fig. 4). Chrysoeriol was absent from both dechlorophyllized samples but was present in both crude sample counterparts. There were two phenolic compounds, salvianic acid and luteolin, that were identified in Medina mint but were absent in Hasawi mint.

The major phenolic compounds identified in Medina and Hasawi mint samples were consistent with those identified in other mint species (Dorman et al. 2003; Zheng and Wang 2001). Caffeic acid (3,4-dihydroxytrans-cinnamic acid) plays an important role in the polar phenolic compounds of mint; the main phenolic acids present were caffeic acid derivatives and polymers (Baliga and Rao 2010). For example, salvianic acid (3, 4dihydroxyphenyllactic acid) is a monomeric compound related to caffeic acid, while rosmarinic acid is the dimer of caffeic acid. The flavonoids identified in Medina and

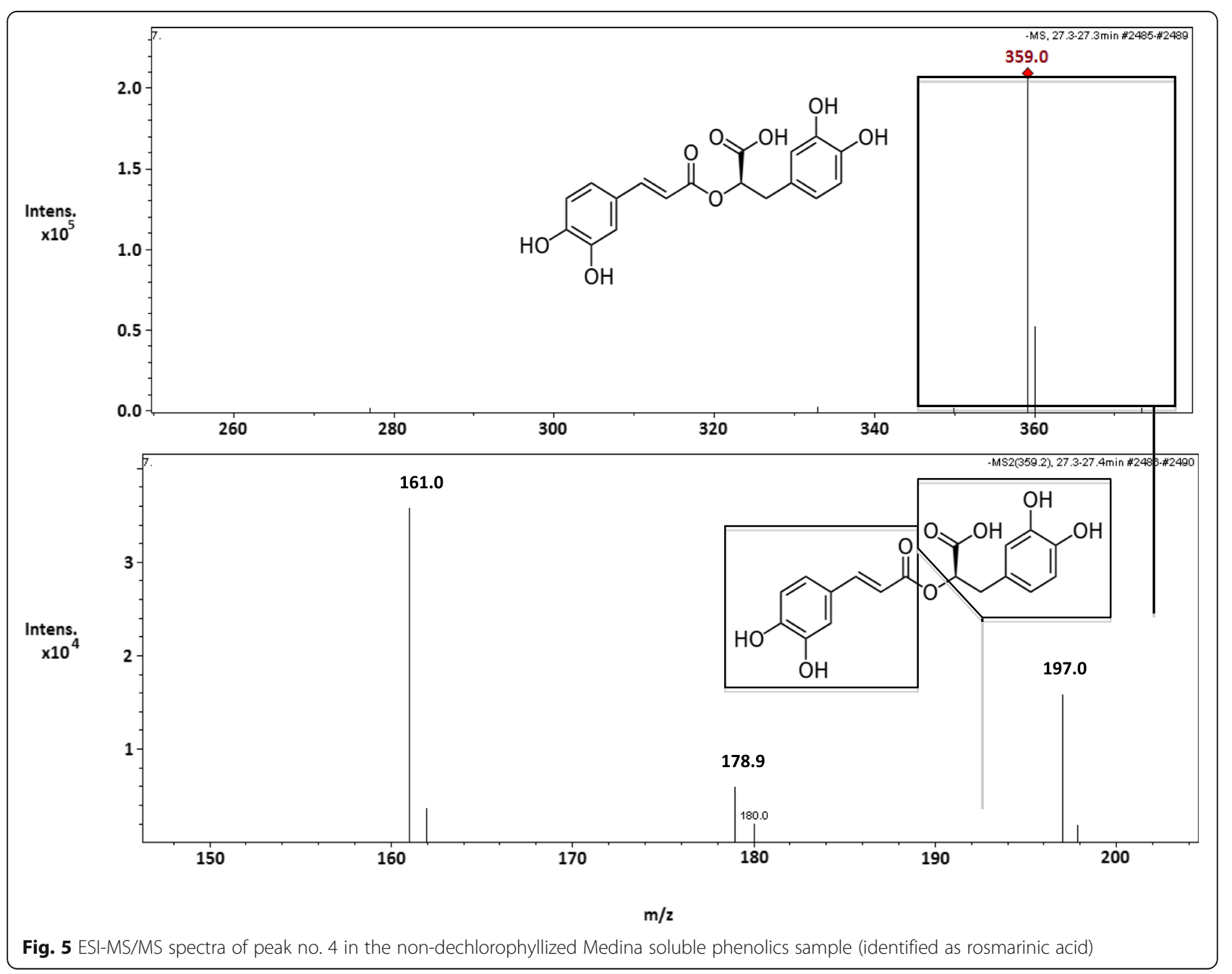


Hasawi mint belonged to the flavone family. One of the compounds identified in both mint samples, carnosol, is not often reported as being present in mint; however, it is a major phenolic compound in rosemary, a relative of mint (Kayashima and Matsubara 2012). Two phenolic compounds, salvianic acid and luteolin, were not identified in the Hasawi mint samples. Moreover, Hasawi mint also contained a relatively lower amount of phenolics as compared to the Medina mint samples which clearly explains their lower antioxidant activities in the different assays performed in this study. Rosmarinic acid, the major phenolic compound present in both mint samples, has confirmed antiviral activity, especially on Herpes simplex virus, as well as a strong anti-helmintic activity (Mimica-Dukic and Bozin 2008).

The HPLC elution order of compounds was consistent with those previously reported by Abad-Garcia et al. (2009). Thus, the retention time decreased with the increase in the number of hydroxyl groups on the polyphenol and polar constituents, such as methoxy groups, resulted in an increase in the retention time (salvigenin vs thymonin). In addition, presence of sugars or acidic groups decreased the retention time for the polyphenols compared to their corresponding aglycones. Thus, presence of highly polar quinic acid made caffeoylquinic acid to elute before the free caffeic acid (retention time $13.2 \mathrm{~min}$, not shown).

In this study we used HPLC/ESI-MS/MS in the negative ionization mode in order to obtain more information about the structural features of phenolic compounds. Negative ion mode was selected because previous findings suggested it was more sensitive than positive mode. This was despite the fact that use of positive mode makes more sense when sodium adducts are involved. The $[\mathrm{M}-\mathrm{H}]^{-}$ ions were selected for collision-induced fragmentation (CID) to produce MS/MS spectra. All of the compounds were found to yield $[\mathrm{M}-\mathrm{H}]^{-}$ions of different masses, except caffeoylquinic acid and salvianic acid, which gave the corresponding $[\mathrm{M}-\mathrm{H}+\mathrm{Na}]^{-}$and $[2 \mathrm{M}-\mathrm{H}]^{-}$ions, respectively. The identification of different phenolic compounds, as listed in Table 4, was confirmed from the MS/MS fragmentation pattern and by comparison with the data obtained in previous studies (Mimica-Dukic and Bozin 2008; Plazonic et al. 2009).

The extracts from the two selected Mentha species analyzed in this study presented high antioxidant activity in terms of oxidation inhibition and free radical scavenging, thus further establishing their possible benefits to human health when present in the diet with exploitable antioxidant properties in vitro. The solvent extracted soluble phenolics in Medina mint appeared to be a better source of natural antioxidants between the two tested varieties with respect to their phenolic contents as well as antioxidant activities. The aqueous infusion of Medina mint, however, had higher iron chelation and LDL cholesterol oxidation inhibition activity in spite of showing lower phenolic contents than the solvent extracted soluble phenolics. Overall, our data suggest that these mint varieties are excellent sources of natural antioxidants. However, further investigations are required to determine if the mint extracts possess in vivo activities before utilizing them in functional food products.

\section{Conclusions}

Mint leaves of Mentha species were found to possess strong antioxidant properties in vitro by displaying free radical scavenging activity. This was also reflected in their iron chelating activity and inhibition of LDL cholesterol oxidation and DNA scission. The compounds responsible for these activities included both phenolic acids and flavonoids. Overall, this study supports the notion that mint leaves and products may lend themselves for use in food formulations and as potential health promoting ingredients.

\section{Acknowledgements}

We are grateful to the Natural Sciences and Engineering Research Council (NSERC) of Canada for partial financial support of this project and to Dr. AlKhalifa for providing the samples. We are also grateful to Mr. Haiqiu (Jason) Huang and Dr. Liangli (Lucy) Yu for the anti-inflammatory experiments.

\section{Authors' contributions}

Authors contributed equality to the reported work. All authors read and approved the final manuscript.

Funding

Authors are grateful to the Natural Sciences and Engineering Research Council of Canada (NSERC) for a Discovery Grant to FS.

Availability of data and materials

Please contact authors for data request.

Competing interests

The authors declare that they have no competing interests.

\section{Author details}

'Department of Biochemistry, Memorial University of Newfoundland, St. John's, NL A1B 3X9, Canada. ${ }^{2}$ Present Address: Department of Food Science and Technology, Kerala University of Fisheries and Ocean Studies, Kochi, Kerala 682506, India.

Received: 5 July 2019 Accepted: 26 July 2019

Published online: 03 September 2019

\section{References}

Abad-Garcia, B., Berrueta, L. A., Garmon-Lobato, S., Gallo, B., \& Vicente, F. (2009). A general analytical strategy for the characterization of phenolic compounds in fruit juices by high-performance liquid chromatography with diode array detection coupled to electrospray ionization and triple quadrupole mass spectrometry. J Chromatogr A, 1216, 5398-5415.

Alvarez-Parrilla, E., de la Rosa, L. A., Amarowicz, R., \& Shahidi, F. (2011). Antioxidant activity of fresh and processed jalapeno and serrano peppers. J Agric Food Chem, 59, 163-173.

Atanassova, M., \& Georgieva, S. (2010). Comparative polyphenol composition and antioxidant capacity of the bulgarian plants (dry herbs). Electr J Environl, Agric Food Chem, 9, 1514-1523.

Atoui, A. K., Mansouri, A., Boskou, G., \& Kefalas, P. (2005). Tea and herbal infusions: their antioxidant activity and phenolic profile. Food Chem, 89, 27-36. 
Azam, S., Hadi, N., Khan, N. U., \& Hadi, S. M. (2004). Prooxidant property of green tea polyphenols epicatechin and epigallocatechin-3-gallate: implications for anticancer properties. Toxicol in Vitro, 18, 555-561.

Baliga, M. S., \& Rao, S. (2010). Radioprotective potential of mint: a brief review. J Cancer ResTherapeut, 6, 255-262.

Bligh, E. G., \& Dyer, W. J. (1959). A rapid method of total lipid extraction and purification. Can J Biochem Physiol, 37, 911-917.

Cavaliere, C. (2009). The effects of climate change on medicinal and aromatic plants. Herbal Gram, 81, 44-57.

Chandrasekara, A., \& Shahidi, F. (2010). Content of insoluble bound phenolics in millets and their contribution to antioxidant capacity. J Agric Food Chem, 58 6706-6714.

Chandrasekara, A., \& Shahidi, F. (2011). Bioactivities and antiradical properties of millet grains and hulls. J Agric Food Chem, 59, 9563-9571.

Choe, E., \& Min, D. B. (2006). Mechanisms and factors for edible oil oxidation. Comprehen Rev Food Sci Food Safety, 5, 169-186.

Dorman, H. J. D., Kosar, M., Kahlos, K., Holm, Y., \& Hiltunen, R. (2003). Antioxidant properties and composition of aqueous extracts from mentha species, hybrids, varieties, and cultivars. J Agric Food Chem, 51, 4563-4569.

Halliwell, B. (1997). Antioxidants and human diseases: a general introduction. Nutr Rev, 55, S44-S51.

Hider, R.C., Liu, Z. D., \& Khodr, H.H. (2001). Metal chelation of polyphenols. In, Packer, L. (Ed.), methods Enzymol., 35: 190-203, Academic Press, San Diego, CA.

Huang, H., Fletcher, A., Niu, Y., Wang, T. T. Y., \& Yu, L. (2012). Characterization of lipopolysaccharide-stimulated cytokine expression in macrophages and monocytes. Inflam Res, 10, 1329-1338.

Kayashima T, Matsubara J.Antiangiogenic effect of carnosic acid and carnosol: neuroprotective compounds in rosemary leaves. Biosci Biotechnol Biochem 2012;76:115-119.

Krygier, K., Sosulski, F., \& Hogge, L. (1982). Free, esterified, and insoluble-bound phenolic-acids .1. Extraction and purification procedure. J Agric Food Chem, 30, 330-334

Kujala, T. S., Loponen, J. M., Klika, K. D., \& Pihlaja, K. (2000). Phenolics and betacyanins in red beetroot (beta vulgaris) root: distribution and effect of cold storage on the content of total phenolics and three individual compounds. J Agric Food Chem, 48, 5338-5342.

Liang, Y. C., Tsai, S. H., Tsai, D. C., Lin-Shiau, S. Y., \& Lin, J. K. (2001). Suppression of inducible cyclooxygenase and nitric oxide synthase through activation of peroxisome proliferator-activated receptor-gamma by flavonoids in mouse macrophages. FEBS Lett, 496, 12-18.

Lopez, V., Martin, S., Gomez-Serranillos, M. P., Carretero, M. E., Jager, A. K., \& Calvo, M. I. (2010). Neuroprotective and neurochemical properties of mint extracts. Phytother Res, 24, 869-874.

Madhuijth, T., \& Shahidi, F. (2007). Antioxidative and antiproliferative properties of selected barley (Hordeum vulgarae L.) cultivars and their potential for inhibition of low-density lipoprotein (Idl) cholesterol oxidation. J Agric Food Chem, 55, 5018-5024

Mata AT, Proenca C, Ferreira AR, Serralheiro MLM, Nogueira JMF, Arango MEM. Antioxidant and antiacetylcholinesterase activities of five plants used as Portugese food spies. Food Chem. 2007;103:778-786.

McKay, D. L., \& Blumberg, J. B. (2006). A review of the bioactivity and potential health benefits of peppermint tea (Mentha piperita I.). Phytother Res, 20, 619-633.

Mimica-Dukic, N., \& Bozin, B. (2008). Mentha I. species (lamiaceae) as promising sources of bioactive secondary metabolites. Curr Pharm Design, 14, 3141-3150.

Mimica-Dukic, N., Jakovljevic, V., Mira, P., Gasic, O., \& Szabo, A. (1996). Pharmacological study of mentha longifolia phenolic extracts. Int $J$ Pharmacog, 34, 359-364.

Moraes-De-Souza, R. A., Oldoni, T. L. C., Regitano-d'Arce, M. A. B., \& Alencar, S. M. (2008). Antioxidant activity and phenolic composition of herbal infusions consumed in Brazil. Ciencia Y Tecnologia Alimentaria, 6, 41-47.

Naczk, M., \& Shahidi, F. (1989). The effect of methanol ammonia water-treatment on the content of phenolic-acids of canola. Food Chem, 31, 159-164.

Naczk, M., \& Shahidi, F. (2004). Extraction and analysis of phenolics in food. J Chromatogr A, 1054, 95-111.

O'Leary, K., Pascual-Tereasa, S., Needs, P. W., Bao, Y., O'Brien, N. M., \& Williamson, G. (2004). Effects of flavonoids and vitamin E on cyclooxygenase (COX-2) transcription. Mut Res, 551, 245-254.

Park, J. B. (2011). Identification and quantification of a major anti-oxidant and anti-inflammatory phenolic compound found in basil, lemon thyme, mint, oregano, rosemary, sage, and thyme. Int J Food Sci Nutr, 62, 577-584.
Plazonic, A., Bucar, F., Males, Z., Mornar, A., Nigovic, B., \& Kujundzic, N. (2009). Identification and quantification of flavonoids and phenolic acids in burr parsley (Caucalis platycarpos L.), using high-performance liquid chromatography with diode array detection and electrospray ionization mass spectrometry. Molecules, 14, 2466-2490.

Politeo, O., Jukic, M., \& Milos, M. (2006). Chemical composition and antioxidant activity of essential oils of twelve spice plants. Croat Chem Acta, 79, 545-552.

Prior, R. L., Wu, X., \& Schaich, K. (2005). Standardized methods for the determination of antioxidant capacity and phenolics in foods and dietary supplements. J Agric Food Chem, 53, 4290-4302.

Raso, G. M., Meli, R., Di Carlo, G., Pacilio, M., \& Di Carlo, R. (2001). Inhibition of inducible nitric oxide synthase and cyclooxygenase-2 expression by flavonoids in macrophage J774A1. Life Sci, 68, 921-931.

Ravn HW, Pedersen MF, Borum J, Andary C. Seasonal variation and distribution of two phenolic compounds, rosmarinic acid and caffeic acid in leaves and roots - rhizomes of eelgrass (Zostera Marina L.). Ophelia. 1994; 40:51-61.

Riedl, K. M., \& Hagerman, A. E. (2001). Tannin-protein complexes as radical scavengers and radical sinks. J Agric Food Chem, 49, 491-4923.

Shahidi, F. (2001). Extraction and measurement of total lipids. In R. E. Wrolstad (Ed.), Current protocols in food analytical chemistry (pp. 425-436). New York, NY: John Wiley \& Sons, Inc.

Shahidi, F., \& Alexander, D. M. (1998). Green tea catechins as inhibitors of oxidation of meat lipids. J Food Lipids, 5, 125-133.

Shahidi, F., \& Zhong, Y. (2009). Antioxidants, polyphenols, and adipose inflammation. In, A.B. Awad and P.G. Bradford (Eds.), Adipose tissue and inflammation, pp. 233-234. CRC Press, Taylor \& Francis Inc., Boca Raton, FL.

Shahidi, F., \& Zhong, Y. (2010). Lipid oxidation and improving the oxidative stability. Chem Soc Rev, 39, 4067-4079.

Siebert, K. J., Troukhanova, N. V., \& Lynn, P. Y. (1996). Nature of polyphenolprotein interactions. J Agric Food Chem, 44, 80-85.

Singleton, V. L., \& Rossi, J. A. (1965). Colorimetry of total phenolics with phosphomolybdic-phosphotungstic acid reagents. Am J Enol Viticult, 16, 144-158.

Tahira, R., Naeemullah, M., Akbar, F., \& Masood, M. S. (2011). Major phenolic acids of local and exotic mint germplasm grown in Islamabad. Pakistan J Bot, 43, 151-154.

Tomas-Barberan, F. A., Gil, M. I., Cremin, P., Waterhouse, A. L., Hess-Pierce, B., \& Kader, A. A. (2001). Hplc-dad-esims analysis of phenolic compounds in nectarines, peaches, and plums. J Agric Food Chem, 49, 4748-4760.

Trasino, S. E., Kim, Y. S., \& Wang, T. T. Y. (2009). Ligand, receptor, and cell typedependent regulation of $A B C A 1$ and $A B C G 1$ mRNA in prostate cancer epithelial cells. Molec Cancer Therap, 8, 1934-1945.

Vokovic-Gacis, B., \& Simic, D. (1993). Identification of natural antimutagens with modulation effects on DNA repair. Basic Life Sci, 6, 269-274.

Wu, S. J., \& Ng, L. T. (2008). Antioxidant and free radical scavenging activities of wild bitter melon (Momordica charantia linn. Var. Abbreviata ser.) in Taiwan. Lwt-Food Sci Technol, 41, 323-330.

Yen, G. C., \& Chen, H. Y. (1995). Antioxidant activity of various tea extracts in relation to their antimutagenicity. J Agric Food Chem, 43, 27-32.

Zheng, W., \& Wang, S. Y. (2001). Antioxidant activity and phenolic compounds in selected herbs. J Agric Food Chem, 49, 5165-5170.

Zhong, Y., Chiou, Y., Pan, M., \& Shahidi, F. (2012). Anti-inflammatory activity of lipophilic epigallocatechin gallate (EGCG) derivatives in LPS-stimulated murine macrophages. Food Chem, 134, 742-748.

Zhong, Y., \& Shahidi, F. (2012). Lipophilised epigallocatechin gallate (EGCG) derivatives and their antioxidant potential in food and biological systems. Food Chem, 131, 22-30.

\section{Publisher's Note}

Springer Nature remains neutral with regard to jurisdictional claims in published maps and institutional affiliations. 